\title{
ERRATUM
}

\section{Climate impacts of energy technologies depend on emissions timing}

Morgan R. Edwards and Jessika E. Trancik

Nature Climate Change 4, 348-352 (2014); published online 25 April 2014; corrected after print 25 April 2014.

In the print version of this Letter, the $y$ axes in Fig. $4 \mathrm{a}$,b should have been labelled 'Impact ( $\mathrm{g} \mathrm{CO}_{2}$-eq km$\left.{ }^{-1}\right)$ '. In addition, the first sentence of the author contributions should have read 'J.E.T. developed the concept and designed the methods for the study'. These errors have been corrected in the HTML and PDF versions of the Letter. 